\title{
Density Assessment of Different Metals and Alloys by Gamma-Ray Transmission Technique via Using Co-60 Radioactive Source
}

\author{
Muttalip Ergun Turgay \\ Electronic and Automation Division, Mustafa Kemal University, Hatay 31001, Turkey
}

\begin{abstract}
In this study, density measurements were observed by using gamma transmission technique. Co-60 gamma emitter was used as gamma radioisotope source. Regarding the gamma-ray transmission method, initial radiation intensity $\left(\mathrm{I}_{0}\right)$ and radiation intensity (I) determined experimentally and $\left[\mathrm{I} / \mathrm{I}_{0}\right]$ rates were calculated and then density of materials could be determined by using Beer-Lambert Equation. Experimental application performed on widespread industrial metals or metal alloys e.g. lead, copper and steel, brass. With this study, it is shown that gamma transmission technique can be used for density measurements.
\end{abstract}

Key words: Co-60, density measurement, metal/alloy, gamma-transmission technique, nuclear applications, nuclear technique.

\section{Introduction}

Last 30 decades, nuclear techniques are used more frequently in many different industrial applications as preferential. Main reasons are: applicable for many products without contact, giving detailed information about inside of material, existing in Non-destructive methods, sometimes unprecedently [1]. Nuclear Techniques are especially used for thickness and density measurement, material analysis, corrosion determination and viscosity measurements. At this point, many radiation types are used for these techniques especially ionized ones as X- and Gamma rays. In this study, Co-60 source was used and main target is to obtain the reliability of this technique.

\section{Theory: Gamma-Ray Transmission Technique}

Due to this technique, gamma-rays loss their energies partially while travelling in the material result of the interaction. Sometimes they travel without any interaction. Commonly, some portion of

Corresponding author: Muttalip Ergun Turgay, Dr., assistant professor, research field: biomedical device technology program. energy will be absorbed by material. Decreasing energy of gamma-ray is seemed as exponential.

$$
\mathrm{I}=\mathrm{I}_{0}[\exp (-\mu x)]
$$

Where, the author shows the radiation intensity as passed to other side of material, $\mathrm{I}_{0}$ is initial radiation intensity, $\mu$ linear absorption coefficient of material, $x$ material thickness. Herewith there are a lot of studies, related gamma ray transmission technique [2-4] are referred from literature. This study is also originated to same technique, too. There are three parameters for gamma-ray interaction to material: energy of gamma-ray which emitted from source, material thickness and material atomic size. It could be written the exponential absorption equation, by means of mass absorption coefficient:

$$
\mathrm{I}=\mathrm{I}_{0}\left[\exp \left(-\mu_{m} x_{m}\right)\right]
$$

Here, the author shows the radiation intensity as passed to other side of material, $\mathrm{I}_{0}$ is initial radiation intensity, $\mu_{m}$ is mass absorption coefficient, $x_{m}$ thickness density of material, and:

$$
\mu_{\mathrm{m}}=\mu / \rho
$$

Where, $\mu$ linear absorption coefficient of material, $\rho$ is material density. $\mathrm{x}_{\mathrm{m}}$ could be written:

$$
\mathrm{x}_{\mathrm{m}}=x \rho
$$


Here, $\mathrm{x}$ shows material thickness and $\rho$ is material density. Eqs. (1) to (4) were referred to the book [5]. For gamma-ray transmission technique, main idea is to follow up the absorption energy of emitted from source. Source and detector would be settled the opposite sides of material for correct geometry of measurement. Fig. 1 shows that geometry:

First step, intensity $\left(\mathrm{I}_{0}\right.$ : radiated from source) was measured without material and then other intensity (I: detected) was measured after material. Measurement could be done by means of comparison between both intensity [6]. In this case, gamma transmission technique could be applied for this kind of measurements. It is easy to apply to materials that on the production band, too.

\section{Density Measurement}

Material thickness should be known in order to obtain density measurement. If material is homogeneous and known the thickness; $\mu_{\mathrm{m}}$ of material is stable and below new equations:

$$
\begin{gathered}
\mathrm{I}=\mathrm{I}_{0}\left(\exp \left[-\mu_{m} \rho x\right] \quad\right) \\
\rho=-\left[\left(1 /\left(x \mu_{m}\right)\right] \ln \left[\mathrm{I} / \mathrm{I}_{0}\right]\right.
\end{gathered}
$$

Which were explained in Ref. [7], $\rho$ shows the density. Furthermore; density measurement by means of Gamma Transmission Technique is usually applied in industrial manufacturing bands. This method is preferred due to avoid time loss and durable.

\section{Methodology: Experimental Works}

Experimental works were done in order to measure densities of different metals and alloys by means of gamma transmission technique. Materials are lead and copper. Alloys are steel and brass. Gamma radioisotope source is Co-60. This source is available and commonly used in many applications [8]. There are two major energy peaks $(1.17,1.33 \mathrm{MeV})$. Half life is 5.27 years and it is appropriate for experimental works. Co-60 source and four different materials were used in experiments and results were recorded for density measurement. Geometry was stabled and each experiment was repeated three times, and then average values were noted. First, background counts were sorted out from gamma energy peaks and net counts were calculated. Co- 60 source and used materials in this experiment were shown in Fig. 2.

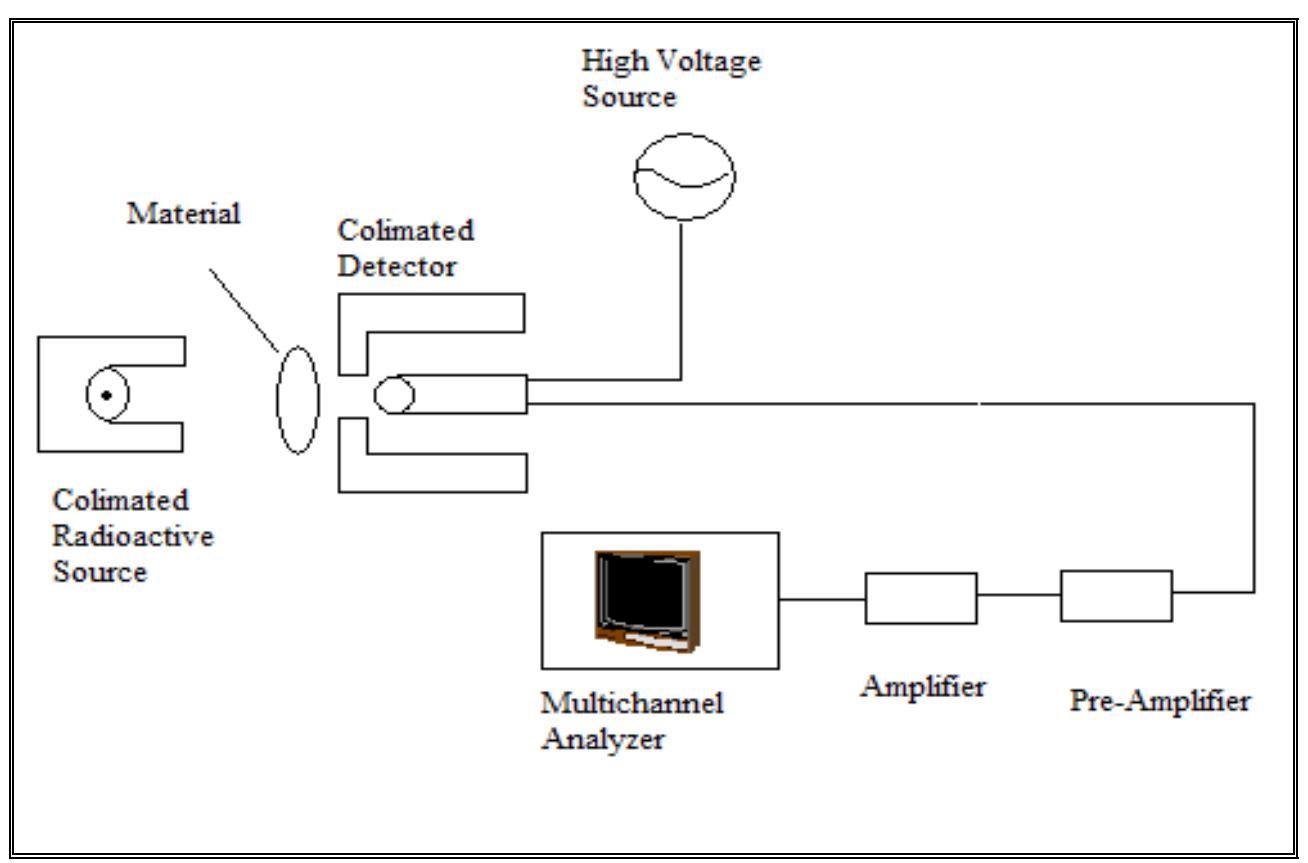

Fig. 1 Gamma transmission technique principle schema. 


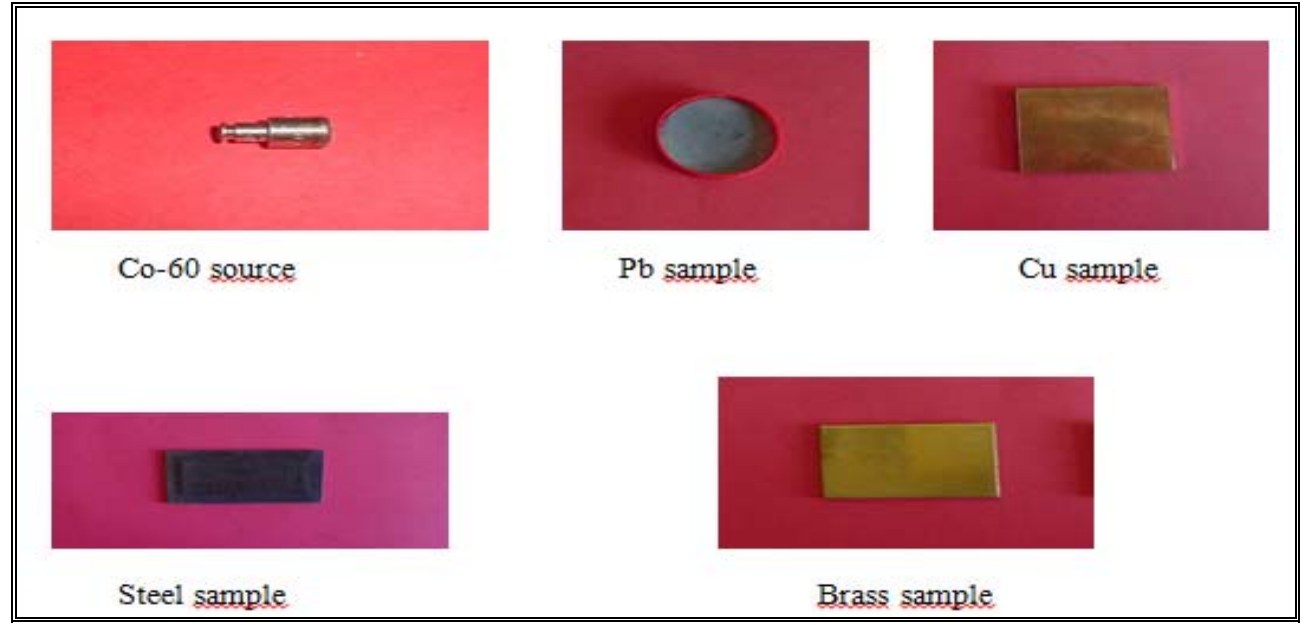

Fig. 2 Source and used material.

Table 1 Count Rates for different samples, counted by Co-60 source.

\begin{tabular}{llllll}
\hline Sample & Background & Count $\left(\mathrm{I}_{0}\right)$ & Average (Triple/3) net count $(\mathrm{I})$ & Standard deviation & Relative count rate $\left(\mathrm{I} / \mathrm{I}_{0}\right)$ \\
\hline Lead & $1 \pm 1$ & $7,861 \pm 89$ & 6,375 & 69.59 & 0.811 \\
Steel & $1 \pm 1$ & $7,861 \pm 89$ & 6,864 & 25.16 & 0.873 \\
Copper & $1 \pm 1$ & $7,815 \pm 88$ & 6,693 & 74.01 & 0.856 \\
Brass & $1 \pm 1$ & $7,861 \pm 89$ & 6,869 & 17.93 & 0.874 \\
\hline
\end{tabular}

Table 2 Obtained densities by Eq. (6), and difference (\%).

\begin{tabular}{lllllll}
\hline Sample & Thickness $(\mathrm{cm})$ & $\begin{array}{l}\mu_{\mathrm{m}} \\
\left(\mathrm{cm}^{2} / \mathrm{g}\right)\end{array}$ & $\begin{array}{l}\text { Relative count rate } \\
\left(\mathrm{I} / \mathrm{I}_{0}\right)\end{array}$ & $\begin{array}{l}\text { Obtained density } \\
\left(\mathrm{g} / \mathrm{cm}^{3}\right)\end{array}$ & $\begin{array}{l}\text { Given density } \\
\left(\mathrm{g} / \mathrm{cm}^{3}\right)\end{array}$ & $\begin{array}{l}\text { Difference } \\
(\%)\end{array}$ \\
\hline Lead & 0.32 & 0.0613 & 0.811 & 10.68 & 11.25 & -5.07 \\
Steel & 0.32 & 0.0544 & 0.873 & 7.82 & 7.80 & 0.26 \\
Copper & 0.32 & 0.0534 & 0.856 & 9.10 & 9.00 & 1.11 \\
Brass & 0.30 & 0.0535 & 0.874 & 8.39 & 8.90 & -5.73 \\
\hline
\end{tabular}

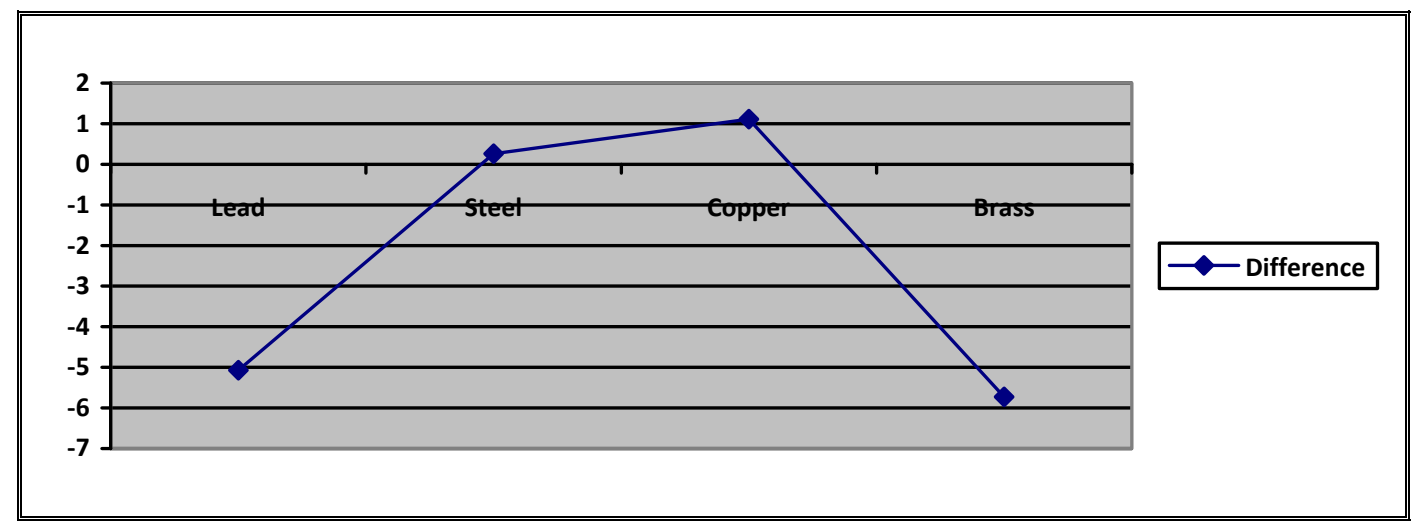

Fig. 3 Difference graphic (Deviation \%).

\section{Results}

All counts were repeated three times and got the average of them. Standard deviations were also calculated. Relative count rates were obtained by means of measuring the radiation which arrived to detector after passed through the sample material. All these data were given in Table 1. Another table numbered 2 was also shown the obtained densities which were calculated by Eq. (6). Now it is possible to compare between Obtained Densities and Given Densities by checking values in Table 2 . 
With this study, it shows that gamma transmission technique can be used for density measurements. There are acceptable differences obtained between the measured densities and given densities of them. In hence, the minimum difference is obtained as $0.26 \%$ (up) for steel and the maximum difference is obtained as $5.73 \%$ (down) for brass. These differences were shown in Table 2 and Fig. 3, too.

\section{Discussion}

Tolerable Difference limits change regarding the subdivisions of industry. For example, this limit is not same between for Space Industry and Manufacturing Industry. Generally, limit is around $10 \%$ for manufacturing industry and nowadays it runs to lower percents. For Space industry, 10 or 5 percent is unacceptable. In this study, Gamma Transmission Technique is checked one time more and generally as results; difference is limited to under $6 \%$ (maximum 5.07 and 5.73 for lead and brass). Although lead and brass, it is realized that, this technique is the more sensitive for steel and copper. These difference ratios would be referenced for next studies about another material's density measurements, too. Finally, it could be said that, this method is reliable for material density measurements especially for industrial manufacturings. This study would be also a baseline for related future Works, for example, same technique via using different gamma-ray source, and/or analyzing by different materials, too.

\section{Acknowledgments}

The author will give many thanks to Asiye Beril Tugrul, a professor at Istanbul Technical University.

\section{References}

[1] Mix, P. E. 1987. Introduction to Non-destructive Testing. New York: John Wiley.

[2] Buyuk, B. 2015. "Gamma Attenuation Behaviour of Some Stainless and Boron Steeels." Acta Physica Polonica A 127: 1342-5.

[3] Buyuk, B., and Tugrul, A. B. 2013. "An Investigation of Gamma Attenuation Behaviour of Titanium Diboride Reinforced Boron-Carbide Silicon Carbide Composites." Radiation Physics and Chemistry.

[4] Karagoz, B., et al. 2011. "Determination of Gamma Transmittance and Density Assessment for Al Doped $\mathrm{ZnO}$ Thin Films By using Gamma Transmission Technique." Defect and Diffusion Forum 312-315: 830-5.

[5] Földiak, G. 1986. "Industrial Application of Radioisotopes." Institute of Isotopes of the Hungarian Academy of Sciences, Budapest.

[6] Gardner, R. P., and Ely, R. L. 1967. Radioisotopes Measurement Applications in Engineering. New York: Reinhold Publishing Co.

[7] Turgay, M. E. 2005. "Density Measurement for Different Metals by Gamma-ray Transmission Technique Used by Radioactive Isotopes.” M.Sc. thesis, Istanbul Technical University, Istanbul.

[8] Bilge, A. N., and Tuğrul, A. B. 1990. Bases of Industrial Radiography. Istanbul: I.T.U. Publishing. 